\title{
SELF DETERMINATION, EMBODIED LANGUAGES AND LANDSCAPES IN WOMEN'S VIDEO ART
}

\author{
Teresa Veiga Furtado \\ Professor at the Department of Visual Arts and Design, University of Évora (UE) and researcher at \\ Centre of Art History and Artistic Research, (CHAIA/UE), and Centre of Research in Social \\ Sciences (CICS.NOVA), Faculty of Social Sciences and Humanities of Universidade Nova de \\ Lisboa (FCSH/UNL), PORTUGAL, tvf@uevora.pt
}

\begin{abstract}
This paper addresses how, since the 1960s to the present, part of women's video art has broken the traditional representation of women's body and proposed new forms of recording women's images, explicit or symbolic, using body part close-ups, and not sparing any efforts to ensure the prevention of the cataloguing of women's bodies according to normative categories, such as gender, race and age, and in this way challenging the Western representation codes that objectify women. The methodology employed had as its primary purpose the examination of the association existing between the micro-sociological level of body gestures and performances in women's videos and the macro-sociological level of social forces such as the dimensions of gender and sexuality. This study concluded that narratives of identity and self-determination are present in women's video pieces contributing to women's empowerment through visual discourses that could possibly point to the production of new signs and symbols, new values and models, but also for the formation of new types of social roles and even a new type of interpersonal relationships.
\end{abstract}

Keywords: Video art, feminism, the Subject, self-determination, gender, body.

\section{INTRODUCTION}

Since the mid-1960s that female artists who displayed their own bodies and addressed women's sexuality in their works were subject to great tension, that was chiefly the product of a Western tradition of representation of the nude in the fine arts, which, in turn, was based on the main foundation defining concept of the man as artist and the woman as model. Up to then the man had, first of all, played the role of master-active-subject, whereas the woman played the role of muse-passive-object of male desire. Regarding her own video production artist Friederike Pezold (Austria, 1945) argues that: «(...) I could stand in front of AND behind the camera at the same time (something I could never do with film). That freed me once and for all of the old dilemma she = nude model, and he = painter, or she as the merchandise of the production» (Stoschek, 2006, p. 138). 
The possibility of building an own subjectivity had been hitherto inhibited by the constant reification of women in mass media culture saturated with images that did not correspond to their Selves. In the 1960s, radical feminists argued that men's violence, which could be seen in domestic violence, rape and sexual harassment, was a central piece for the supremacy of men over women and, to the extent that patriarchy was a systemic phenomenon, equality could only be achieved if the patriarchal order was destroyed (Giddens, Sutton, 2014, p. 101). Gender inequality was apparent in the way men's and women's day-to-day interactions occurred, as in the case of non-verbal communication, listening to and interrupting the speaker, and the welfare of women in public spaces. Moreover, according to radical feminists, the traditional standards of beauty and sexuality were imposed on women, encouraging them to have bodies in accordance with the values in force, as well as displaying compassionate and protective attitudes towards others, which helped to perpetuate their subordination, while being represented in «media», fashion and advertising as sex objects to please men. Later, in the 1990s, feminist authors based on empirical research reworked the concept of patriarchy, and Sylvia Walby replaced it with the idea of public and private gender regime. However, although in the 20th century there has been a profound change from a private to a public gender regime and women have, for example, a greater presence in formal employment, that doesn't mean that gender equality has been achieved today. In fact, women often continue to receive lower salaries than men, are faced with male violence in public spaces, suffer from a sexual double standard and are confronted by women's sexualized representations in mass media and on the Internet (Giddens, Sutton, 2014, p. 101).

\section{THE OBJECT OF THE STUDY}

Our interest in this study was, namely, the analysis of individuation and subjectivity and how these had been addressed by female feminist video artists in their works, in particular in three videos that have in common the fact of being explicit or symbolic records of body parts in great dimension close-ups, thus breaking traditional body unity and proposing new representation fashions that prevent the cataloguing of the bodies of women according to regulatory categories, as those of gender, race and age, and therefore challenging the Western representation codes that objectify women.

\section{RESEARCH STRATEGY AND METHODOLOGICAL TOOLS}

The methodology used for the analysis of video pieces aimed fundamentally at building a link between the micro-sociological level of expressions, behaviours and body gestures in the studied works and the macrosociological plane of broader social forces, both institutionalized and the origin of inequalities, as the forces of gender and «race». We started by dividing an initial set of 50 videos into two subgroups, namely the group of videos having has dominant theme «Subject as Main Agent» and the group of those works whose dominant theme is "Non-subject as Main Agent». However, it was not possible to clearly identify a sociological agent or subject in four of those videos, as none of the content analysis categories we used to study the initial group of 50 videos, and linked to the subject or the non-subject, could be recognized in these four videos. As we have studied one of the videos in a separate article - Mary Coble, Session One (USA, 2007) -, a video where social forces prevent the construction of the self, we are now studying the remaining three video pieces, which deal with the affirmation of identity and the creation of the self in a positive and assertive fashion. The following are the three videos we will be studying:

- Friederike Pezold, Die neue Zeichensprache leibhaftige (Germany, 1973-77).

- Nan Hoover, Desert (Holland, 1985).

- Karla Solano, Canvas (Costa Rica, 2001).

This analysis, qualitative in nature, was mainly supported by secondary sources outside of the videos themselves, that is, additional information not included explicitly or implicitly in the video woks, such as texts about the artists, interviews with them, etc..

\section{CONTROVERSY AROUND THE REPRESENTATIONS OF THE FEMALE BODY: REIFIED OR SUBJECTIFIED BODIES IMAGES?}

\subsection{Claiming the representation of the body and the pleasure of woman}

The feminist women artists of the 1960s and 1970s faced the issue of women, up until then, not being allowed the recognition of their own sexual fantasies and being socially encouraged to build and live their sex life with the purpose of satisfying male wishes and fantasies. Carolle Schneemann apud Juhasz says that: "The only models for open female sexuality in the early seventies were the boyfuck orgies of hippie culture, the Living Theater gangband model, the porn movies to which all cool girls had to accompany their 
boyfriends» (Schneemann apud Juhasz, 2001, p. 61-62).

In 1976, the controversial study of Shere Hite on female sexual practices in the United States, alerted citizens to the myth of female orgasm and sparked a debate about whether it would be clitoral or vaginal stimulation the one more suited to female sexuality (Phelan, Reckitt, 2001, p. 23). This debate about female sexuality, first highlighted aspects of women's sexuality that had until then been neglected, and, despite at the time being often described, very simplistically, as centred exclusively on the issue of the opposition between lesbianism and heterosexuality, having then been created the motto "feminism is the theory, lesbianism is the practice», which, in turn, resulted from the imperative felt by feminists, to establish a presentable and scientific image of feminism for the masses. In fact, the debates about sexuality were much more complex than those exposed by Shere Hite and reflected some of the most controversial and stimulating aspects of women's emancipation, as was demonstrated by the controversy about whether pornography was criminal and the result of sexual abuse or just a radical form of sexual pleasure, about sadomasochistic relationships, and about women's right to abortion and to control their own body both medically and in legal terms.

The themes of the body and of women's sexual pleasure, developed by feminism in the 1970s, caused feminist female artists to have a new interest in women's body image. Women feminist cinema theorists wondered, on the one hand, whether the pleasure of women viewers resulted from their identification with the image of the woman on the screen or of their very desire for the woman shown, and, on the other, because women are culturally associated with the sexual sphere, about how this association could be used to serve women rather than to oppress them. Even after the ability to control pregnancy was conquered, which was widespread after the creation of the pill in 1960, it still took some time until the sexuality of women became an area of creativity and reinvention (Phelan, Reckitt, 2001, pp. 22-31).

In the 1960s and 1970s, women artists resorted to body and sexuality policies, advocated by women feminists to question the images of women disseminated by mass media and by medical and artistic discourses, which denied female experiences in relation to their own bodies and sexual desires. These discourses were regarded as repressive mechanisms that sought to regulate and contain the right of women to self-determination. In general terms, the objective of female artists was to change woman's traditional place as passive object to that of a speaking artist and subject. Feminist art defended the right of women to represent their bodies and sexualities through images of their genitals and to examine topics considered taboo, as was the case of menstruation.

In the 1970s, accompanying the claim of free expression of sexuality by student, gay, lesbian and feminist movements, several women artists addressed issues relating to body liberation and as well as the emancipation of the culturally repressed female sexual desire. They argued that their bodies' language could not continue to be represented through the traditional cultural cartography. Numerous female artists experienced their own body through Dionysian excesses, as was the case with Carolle Schneemann, who held performances with nude bodies, animals and other items of nature traditionally considered to be dangerous, aggressive or disgusting.

However, in general, artworks celebrated the universal category of woman as feminist theory invoked the common aspects in the lives of women, claiming them as the foundation of a feminine aesthetic. Later, in the 1980s, this trend was criticized by essentialism's concept of the feminine. However, there were some exceptions from female artists who built an aesthetic around the concepts of woman and of female body while at the same time recognizing femininity as socially and historically constructed. Their work analysed, in particular, the aesthetics of the customary representation of woman and the hyperbolized hygienization of the female body within patriarchal culture, revealing woman's body as matter in constant becoming, as opposed to its figuration as form and stasis in traditional fine arts. These female artists' images, videos and performances destroyed Kantian aesthetics conventions, making perceivable some aspects of the female body that could not be represented according to those protocols. As a result, since the 1960s up to the present day, representations made by women artists about sexual desire separated from the duties of marriage and motherhood undermine the traditional normative vision of female sexuality, while raising fierce social criticism and contentious debates in the artistic world.

\subsection{The danger of appropriation of the female body by the patriarchal objectifying look}

In 1976, Lippard said she wasn't at all surprised by the fact that women artists, consciously or unconsciously, so often used images of their own bodies, since throughout their lives they had learnt that their personal appearance affected the course of their own destiny. Thus, female artists took advantage of their own bodies 
in order to please male audiences. Lippard considered at best tenuous the difference between the use of the woman's body by society as an object of sexual gratification, and the use of the woman's body by the artists, as a criticism of this reifying social process. On the subject of Hannah Wilke's work, who since the mid1960s, used depictions of female sexuality using her own body, Lippard advocated that women who questioned the rules by displaying their nude bodies, were more vulnerable to criticism, both personally and artistically, when exhibiting beautiful bodies. Lippard argued that Wilke due to her own confusion when it came to her roles as beautiful woman and artist, as well as glamorous and feminist individual, created at times politically ambiguous works and interventions that have been the subject of personal and artistic criticism (Lippard, 1976, p. 126).

In this regard, Wark (2006, pp. 58-67), disagrees with the assertion that performance was appealing to women artists mainly for constituting a new and open field free of male dominance, since the 1960s to the early 1970s, body art was a predominantly masculine art form, as was the case, in fact, with minimalism and conceptualism. Between 1967 and 1971, artistic manifestations of male sexuality, such as those carried out by Vito Acconci, who masturbated in his performances, provoked in women artists a sense of distrust in relation to this art form because, having just come off from a period of artistic isolation and finding themselves in a vulnerable position, such practices, which they perceived as aggressive, did not appear as the best way to enter the world of performance. Similarly, in the 1970s, Lippard warned women artists that, while they had full right to display their own bodies, up until then reified in art, and to assert their subjectivity, they were incurring the danger of being appropriated by the male gaze as sexual pleasure objects.

From the 1960s, women sought to assert and control their sexuality in the social sphere and, when, during the same period, they entered the territory of art until then inhabited primarily by male artists, female artists sought to use their creative energies to express women's sexualities, which had been culturally repressed. In the 1980s, women artists who in previous decades had approached female sexuality through their own bodies were deeply criticized as essentialist and ambiguous in their deconstruction of the patriarchal sexual standards. Feminist criticism, made between the 1970s and the mid-1980s, by Lippard, Tickner, Pollock and Parker, and Mary Kelly, among many others, considered often as politically ambiguous the manifestations used by women to parody in art the reifying sexual roles society attributed to them and imposed upon them in real life. In the late 1980s, Lisa Tickner argued that women artists don't only need to be sexually free to produce erotic art, what they need, above all, is freedom within the artistic sphere. The central reasons that had prevented women from performing an erotic iconography were the same that had prevented them from participating in the construction of art history: the exclusion from artistic institutions and the constant suppression of their sexuality in favour of male fantasies (Tickner, 1989, p. 239).

In 1981, Pollock and Parker warned, as Lippard had done in the mid-1970s, to the danger of artwork, addressing female sexuality through the representation of its biology, in this way identifying woman with the kingdom of nature, thus helping to perpetuate the characterization of her subjectivity as non-cultural and exclusively corporal and sexual, unlike the male subject systematically portrayed as associated with culture and transcendence. In the context of a social organization in which masculinity and femininity were welldefined and standardized cultural positions, and femininity does not constitute an alternative to masculinity but is perceived as its negative, it was not possible for female artists to create alternative meanings regarding their bodies. They were left with the option of deconstructing the sexual standards in force through exposure of the ideological models of sexual difference that built and defined art and artists (Pollock, Parker, 1981, pp. 132-133).

Another cause for the conflict, caused by women artists who used their bodies, was the issue of narcissism. If, on the one hand, in the 1970s, narcissism was a derogatory term, applied too generally, in art and in society, to vanity, self-satisfaction and self-glorification, and the criticism of the video as narcissistic medium was made exactly with that meaning, on the other hand, its association with femininity revealed the lack of recognition by society of the importance of self-representation of women as an artistic theme. The term narcissism was, however, rehabilitated by feminists as Amelia Jones and Jo Anna Isaak, who interpreted it positively, considering that narcissistic self-reflection presented a high potential of political resistance, having in addition, resorted to Freudian analysis to understand feminine self-contentment as a way to compensate for the social restrictions imposed on women by the choice of man as love object, in this way making up for narcissism of women and their lack of phallus (Wark, 2006, pp. 58-67).

\subsection{Defense of the right to the representation of the body by women artists argued by feminisms}

In the 1990s, feminists like Amelia Jones and Laura Kipnis, rose up against the feminist women theoreticians of the previous decade, who had themselves attacked the representations of the body of the 1970s, which 
they thought were essentialist. Kipnis refuted the arguments of feminist criticism of the 1980s, claiming that once the concept of gender is defined in western culture according to the dictates of the church, the state and the social body, and because cultural industries of representation are organized around issues regarding a hierarchized sexual difference and phallic power that delete female pleasure and sexual desire, which is itself represented and constituted around the phallus, this results in the fact that women artists have every right to assert their sexuality in the artistic sphere. Kipnis argues that several women video artists, mostly lesbians, affirm their sexuality and refuse the traditional dictates of feminist film theory that organizes visual pleasure around sexuality and the heterosexual male gaze. When rejecting feminist dichotomies of oppressor/victim, looking subject/object that is looked upon and male pornography/female erotic, these women artists invent new aesthetic and policy formulae and substitute a self-victimizing female identity with an assertive and autonomous subjectivity. These women video artists put again the emphasis on the important issue of the representation of the pleasure of women in art. Mulvey's essay «Visual Pleasure and Narrative Cinema», written in 1975, positions the analysis of how Hollywood's scopophilic movie regime understands women on the list of priorities of the generation of women theoreticians and feminist film creators of her time. This essay describes male viewers' voyeuristic and fetishistic answers to images of women, and is the first attempt to analyse the interaction between the viewer and the screen from a feminist perspective. However, and notwithstanding the important contributions made by Mulvey to feminist film theory, there came to flourish as a result of her analyses, a modernist elitist counter-cinema that, if, on the one hand, constituted an antidote against the power of the male gaze, on the other hand, could only be understood by an elite, a culturally erudite public (Kipnis, 1996, p. 334). Inadvertently, Mulvey in wishing to reform male imagination and sexuality mainly attacked the audience belonging to the popular masses and its scopophilic pleasures.

When it comes to feminist criticisms fenced between different generations, criticism directed against a defined time is often biased and limiting as it does not contemplate the variety of themes and strategies that feminist artists adopt in a particular historical, geographical and political period, focusing solely on a specific sector and excluding other equally important perspectives. Defending women artists who represented their body in the 1960s and 1970s, Wark (2006, pp. 58-67) argues that, although these artists have held figurations of their sexuality often in a literal fashion, and despite vehement criticism from theoreticians on essentialist body representations, this does not constitute an obstruction to the fact that, in the 1980s, women artists continued the research initiated in previous decades on that theme. During the new millennium, as had happened in previous periods, several artists addressed issues of sexuality and claimed the right to display themselves as sexual objects. However, amongst these artists, there are those that although claiming to resort to feminism as a conceptual support, in fact devoid their work, completely from feministic content, using their bodies to express a sexuality that does not challenge conventional representations of women as objects of the traditional erotic spectacle. These liberating assertions affirming women's right to pleasure in their own sexuality, do not reject nor contradict, however, the capitalist and patriarchal social ideals of exploitation of women's bodies, because they appeal to a reification of the bodies traditionally considered suitable: bodies of young, skinny white women. So, feminism as a collective political movement, whose greatest contribution to the art world was its politicization, is entirely absent from these individualistic stylizations of mercantile character that feminist art always sought to expose and criticize (Wark, 2006, pp. 58-67).

\section{WOMEN CREATING THEIR OWN SELVES THROUGH FRAGMENTED, ABSTRACTIFIED AND SUGGESTED BODIES}

\subsection{Embodied Signs}

In the 1960s, artist Friederike Pezold dedicated herself to the representation of the female body that she considered being the measure of all things and the main element of a new body language and sensual architecture, based on the laws of anatomy, geometry and kinetics (Moisdon, 1992, p. 238). Through video and installation, the artist performs a critical reflection on the social role of the female body, proposing a new embodiment represented by abstract graphical structures in the shape of new visual signs. In her videos the images of less erotic body parts, such as the elbows, feet, knees and shoulders, are transformed, through a particular image registration technique mainly based on close-ups, resulting in depictions with a previously absent sensual charge (Lippard, 1976, p. 129). Pezold manipulates the body, in order to create patterns of light and shadow, which can be interpreted, on the one hand, as two-dimensional abstract forms that are slowly changing, and, on the other, as bodily landscapes. In her video Die neue Zeichensprache leibhaftige (The New Embodied Sign Language) (Germany, 1973-77) the artist shows sequences, with about ten minutes each, from close-ups of different parts of her own body - Schamwerk (genital work), Brustwerk 
(breast work), Schenkelwerk (thigh work), Armwerk (arm work) and Mundwerk (mouth work). This video was later exhibited at the documenta exhibition in Kassel, in 1977, in a room lined with Tatami mats (Media Art Net, 2009). Her videos were several times presented on monitors grouped according to multiple anthropomorphic sculptures, and titled differently, such as Madame Cucumatz, 1975, a video sculpture composed of five stacked video monitors that suggest a female figure, or Göttin Körpertempel (The Goddess' Temple of the Body). This reference to the goddesses appears in Pezold's work and also in that of several other women artists of this period, as is the case of Ulrike Rosenbach and Ana Mendieta. These allusions are the result of the artists seeking for different reference systems from the existing patriarchal system, which would be structures that women could use as support to help them build their own subjectivities. Pezold asserts: «While operating with video on a new technical level, I could make possible what had been impossible until now: to cancel out the separation of model and painter, of subject and object, of image and likeness. Through the simultaneous recording and playing back, I could also be in the present, past, and future at the same time. I gained a new sense of time. Instead of looking through the lens of a camera, now I looked at the large surface of the TV monitor's screen. All at once I saw everything as if through a magnifying glass... That was how I rediscovered the body and all its regions - and invented a new body language. New personified signs of the body within a new movement» (STOSCHEK, Jeannette, 2006, p. 138).

The artist intends to reject a «tele-vision» in order to adopt a close and extreme vision of the parts of her body, which would then assume a graphic and abstract character (Media art Net, 2009). The images can be seen as abstract paintings that embrace temporality through slow motion of body forms. The body moves slowly, producing different images, which, by their formal characteristics, are similar to the abstract works of minimalist artists active in that period, as Carl André, Donald Judd and Richard Serra. However, despite the images being very close to minimalist graphic shapes, Pezold's video, unlike minimalist objects, is not selfreferential, but rather a reflection on social structures, full of associations and meanings. Pezold's images differ from those found in minimalistic works, to the extent that the artist wants to show her own perspective about women's body and sexuality, and opposes it to the perspective of mass media, which in turn reduce femininity to an object. Similarly, black and white images without sound and movements performed at a slow pace and in loop reject the traditional linguistic codes present in mass media. Her video refuses the representation of a woman's body as a sign of the male voyeuristic desire and proposes a new language hence the title «The New Embodied Sign Language» - which takes advantage of signs made from parts of the woman's body. The different parts of the woman's body take the form of graphics signs producing various meanings and are no longer mere projection surfaces for ideas originating from the patriarchal imagery. These «embodied signs» are made up of carefully stylized images, in which the colours black and white are intentionally applied to the surface of the body, in order to two-dimensionalize the picture and strengthen its limits, either concave or convex, while playing with different body masses that cast tenuous shadows on one another. The resulting figures evoke the signs of oriental writing, creating a «sensuous architecture» (Stoschek, 2006, p. 136).

\subsection{Embodied landscapes}

Just as Pezold, artist Nan Hoover (USA, 1931-2008), created images that record or evoke the female body in an abstract fashion, which makes difficult their appropriation in a sexual way. Hoover, originally trained in painting, moved to the Netherlands in 1969, where she conducted several projects in video and performance. Her videos, which are records of both external and interiors environments, evoke landscapes in motion.

In the video Desert (Holland, 1985) the artist registers a piece of ochre paper, from a camera's fixed point of view, while nothing moves besides the light that keeps revealing different features of the folded paper. The action unfolds with the transitions of light, and both the movement as well as the video's temporal dimension are the result of light intensity variations in the shapes filmed by the artist that, in turn, appear to take several diverse volumes throughout the video. Through the manipulation of light, Hoover introduces the temporal factor, modelling the material in such a way as to reveal to the viewer different volumes and shades, over the duration of the video. Using the dramatic play of light and shadow - the palette ranges from yellow to black the "sand banks" in a way suggested by the video title, remind us of sculptural landscapes and sensual body images. The observer participates through their imagination to build an oneiric context for these abstract shapes. The video has no sound and the tranquillity created by silence is an essential element for the reading of these images of meditative nature. The artist paints pictures in motion through the light. The changes of light suggest the movement of the sun throughout the day, revealing caves, hills and other reliefs and geographical recesses (a map either of the landscape or of the body) that keep metamorphosing into their opposites - the reliefs become cavities and vice versa, for example - through the magic manipulation of 
light by the artist. Accidents of this inner landscape appear and disappear. That which in a given moment seems to be a valley soon gains volume and turns into a slope; a horizontal flat plane becomes a sinuous landscape. All these elements are, throughout the video, regularly covered or uncovered, in tonal gradations of high contrast, caused by slow and subtle movements of illumination and shadow, ranging from strong brightness to the total absence of light.

Other videos by this artist record abstract forms or natural landscape or architectural elements that evoke bodies, as well as organic or inorganic elements. Light, pictorial space, movement and time are the fundamental elements of her work. All her works present an aesthetic, poetic and pictorial character and an internal rhythm of meditative nature, created by the slow, precise and subtle light and shadow movements, on the shapes (Zippay, 1991, p. 110). Her quiescent timeless landscapes, with the camera usually fixed, as well as not editing images and the very slow and subtle movements of light are factors that contribute to the creation of an atmosphere that invites to meditation. The abstract figures create subtle visual ambiguities and uncertainties in the spectator as to its nature, evoking bodies, niches, rocks, forests and primordial landscapes, among other forms. Tensions between abstraction and reality caused by the orchestration of light, which creates illusions regarding the scale, shape, spatial location and temporality of the volumes, force the viewer to ponder the illusory nature of visual perception. The metaphorical and enigmatic nature of the images transforms the act of visual perception into a predominantly mental experience of complex dimension. The spectator is invited to participate in the creation of the work, and to mentally and imaginatively solve the ambivalence of reality created by the images while exploring the author's personal and creative universe.

Hoover says: "So, as you can see, most of my work explores perception, how we see, or in most cases today, that we do not perceive, we look but do not digest. I think the only way to stimulate the process of perceiving is to confuse, perhaps, to present the question, like Plato, to ask questions and not to give answers, for me there are no answers and our quest, our striving, our search, the search, is what interests me» (Galerie Ernst Hilger, 2009).

\subsection{Abstractified body close ups}

The artist Karla Solano (Costa Rica, 1971), in the same way as Hoover and Pezold, reflects about the body in her photographic and video works. She usually employs images of her own body fragmented and enlarged, sometimes using other corporal cultural codes, such as those from medicine ( $\mathrm{x}$-rays, anatomic schemes) and the ones socially imposed on women (make-up) or poetic and generational when the artist combines her body with her mother's and her daughter's while associating everyone with objects. In a conservative society that rejects this type of approach, the skin and the body fluids, as milk or blood, are recurring elements in her works, always represented in close ups recorded through macro lenses. In some works, she focuses on small fragments of the body revealing their implicit sculptural features while creating a relationship between body and landscape. Sometimes, she builds large installations, body architectures, spaces covered with photographic fragments enlarged from her own body, which require a physical and spiritual participation of the viewer, creating predominantly relational pieces.

In the video Canvas (Costa Rica, 2001) Solano records herself, with a video camera in one hand, in closeups, applying and cleaning makeup in different parts of her naked body, turning herself into a kind of canvas, a sensual landscape. The artist represents herself in a gesture of domain and self-control over her own body. Solano turns her body into a canvas while she is simultaneously painter and model, master and muse. Her skin and hair acquire aesthetic and pictorial qualities, as surfaces, while the artist rejects to display her body in full view, refusing any traditional voyeuristic appropriation. Her scrutiny of the body is not a simple variant of portrait or the nude, nor a simple narcissistic analysis, but rather an introspective look, which combines various languages and cultural codes (Lopez, 2007).

Although the female body in Central America is often a place of suffering, it can also be associated with the idea of contemplation, as Solano does, by means of her poetic reflections on the body. Throughout her work Solano has been more interested in issues of body poetic and not in topics of violence. It is important to stress that the feminist movements that took place in North America and Europe, in the 1960s and 1970s, affected at the same time Central America only to a degree and took different forms depending on the country, due to the specificity of the political unrest and armed conflicts in each nation (Pérez-Ratton, 2007, p. 123).

Even women who participated directly in regional wars and fought in the guerrillas did not do it in conditions of equality with their male companions and many of them have suffered from mistreatment and abuse at masculine hands, which mirrors the general situation of women in society and, in particular, in rural areas. The notion of feminism, as a movement and a way to resist to inequalities, only reached women with access 
to higher education and the possibility to travel. Women in developing countries have very different expectations from those living in developed countries. Inequality appears on the grounds of gender but also of class and of «race», among others. In domestic gender regimes power processes exclude women both from power and influence (Walby, 2011, p. 66).

Nevertheless, many voices have emerged in recent years challenging the patriarchal discourse, including those of numerous women linked to the cultural field - artists, curators, cultural agents and directors of institutions. In Costa Rica, between 1994 and 1998, twenty-seven out of a total of twenty-nine directors of artistic institutions were women. And even if, up to the 1980s, the art in Central America was primarily a world dominated by male artists, from the 1990s women artists emerged with very vigorous works. Women have since been included in the social world, as decision makers, through the choice of a relationship with power that is different from the traditional patriarchal one, contributing to the transformation of the world drawn by men and thus determining a gradual, but steady nonviolent revolution (Pérez-Ratton, 2007, p. 123).

\section{CONCLUSION}

In the 1970s, many feminist thinkers reacted negatively to women artists' depictions of nude bodies, disapproving of them because they were degrading and subject to appropriation by a patriarchal gaze, refusing viewers the possibility of any feelings of pleasure, satisfaction and positive identification when observing those images, even from any female audiences which did not identify with that regard. Consequently, feminist art in the 1970s and 1980s was divided between body celebrations, by artists like Carolee Schneemann, Annie Sprinkle, Ann Magnuson and Hannah Wilke, and depictions by artists such as Friederike Pezold, Mary Lucier, Elsa Stansfield and Madeleine Hookyaas, who sought not to stress women's biology, fearing to fall into the artifice of traditional objectifying iconography.

We think that feminist criticism regarding artworks that rely on bodily depictions is rather limiting as it deals with this issue as if women's bodies exist exclusively as objects for the projection of the masculine gaze and desire, rejecting the reality of other gazes that don't submit to normative heterosexuality. If we consider only a public informed by a patriarchal culture and imagination, in fact these images do not disrupt the meanings of woman as body, sex, nature or object of male ownership. However, when we consider and analyse these artworks, we must take into account the existence of audiences including viewers who do not conform to current gender identity standards. These, in turn, either assert a male consumerist position or passively identify with the objectified woman on the screen. Even though we may agree with these feminist authors with regard to the development of a rigorous analysis and deconstruction of female sexuality in terms of artistic production and reception, we believe that it is possible to produce images of women's sexuality that self-depict them in an assertive, positive and autonomous way, according to their own unconscious and fantasies, their fears and their hopes. We recognize, however, that representing female desire so that it is both heterosexual and transgressive is, in heteronormative cultural contexts dominated by male sexuality, particularly hard.

\section{ACKNOWLEDGEMENTS}

This research was financially supported by: CHAIA - Centre of Art History and Artistic Research, University of Évora; FCT - Foundation of Science and Technology, Portugal.

\section{REFERENCE LIST}

Frederike Pezold: The New Embodied Sign Language". [Online] [Consult. 2009-03-01]. Media Art Net | Frederike Pezold, Embodied: The New Sign Language. http://www.mediaartnet.org/works/leibhaftigezeichensprache/images/3/.

Galerie Ernst Hilger - Solo show: Nan Hoover". [Online] [Consult. 2009-06-01]. Overview - Solo show: Nan Hoover - Hilger modern. http://www.artfacts.net/en/exhibition/nan-hoover-10543/overview.html

Elwes, C. (2005). Video Art, a Guided Tour. London: I.B. Tauris.

Giddens; A.; Sutton, p. w. (2014). Essential Concepts in Sociology. Cambridge: Polity Press.

Kipnis, L. (1996). "Female Transgression. In Resolutions: Contemporary Video Practices". In Renov, M.; 
Suderburg, E. (eds.). Resolutions: Contemporary Video Practices. Minneapolis: University of Minnesota Press.

Lippard, L. R. (1976). From the Center: Feminist Essays on Women's Art. United States of America: Dutton.

López, S. (2007). "Karla Solano: fotografía, espacios y arquitectura". [Online] [Consult. 2009-03-04]. ARTMEDIA. (julio 07). Karla Solano-Costa Rica Contemporary Photography. http://www.karlasolano.com/.

Moisdon, S. (1992). "Friederike Pezold". In Vidéo et aprés. La collection vidéo du Musée national d'art moderne Centre Georges Pompidou. [Catalog]. Paris: Éditions du Centre Georges Pompidou.

Pérez-Ratton, V. (2007). "Central American Women Artists in a Global Age". In Global Feminisms. [Catalog]. London: Merrell Publishers Limited in association with Brooklyn Museum.

Phelan, P. (2001). "Survey". In Reckitt, H; Phelan, p. (eds.). Art and Feminism. London: Phaidon Press.

Pollock, G.; Parker, R. (1981). Old Mistresses: Women, Art and Ideology. Great Britain: Rivers Oram Press/Pandora.

Schneemann, C. apud Juhasz A. (ed.) (2001). Women of Vision: Histories in Feminist Film and Video. Minneapolis: University of Minnesota Press.

Stoschek, J. (2006). "Die Neue Leibhaftige Zeichensprache. Friederike Pezold". In Frieling, R.; Herzogenrath, W. (eds.). 40yearsvideoart.De-Part 1: Digital Heritage: Video Art in Germany from 1963 to the Present. Germany: Hatje Cantz.

Tickner, L. (1989). "The body politic: female sexuality and women artists since 1970". In Betterton, R. (ed.). Looking On. Images of Femininity in the Visual Arts and Media. London: Pandora Press,

Walby, S. (2011). The Future of Feminism. UK: Polity.

Wark, J. (2006). Radical gestures: feminism and performance art in North America, 1970-2000. Canada: McGill-Queen's University Press.

Zippay, L. (1991). Artists' Video: An International Guide. Electronic Arts Intermix. [Catalog]. New York: Electronic Arts Intermix. 